\title{
Assessing the nutritional needs of men with prostate cancer
}

\author{
Kaitlin McLaughlin ${ }^{1}$, Lindsay Hedden ${ }^{1,2,3}$, Philip Pollock ${ }^{3}$, Celestia Higano ${ }^{3,4,5}$ and Rachel A. Murphy ${ }^{1 *}$ (D)
}

\begin{abstract}
Background: Nutrition is important for prostate cancer (PC) survivorship care to help achieve a healthy weight, reduce treatment side effects and reduce the risk of developing other chronic diseases. We aimed to advance the understanding of the nutritional needs of men with PC and services that could be potentially implemented to address them.

Methods: We conducted a needs assessment of nutrition services for men with PC drawing on four perspectives; 1) patient evaluation of a nutrition education session in British Columbia (BC), 2) survey of $B C$ health professionals, 3) an environmental scan of existing nutrition services across Canada and 4) a scoping literature review.
\end{abstract}

Results: Patients expressed a need for more nutrition information and a desire for additional nutrition services. More than $60 \%$ of health professionals believed there is a need for more nutrition services for men with PC, and reported the focus should be on weight management or management of PC progression. The environmental scan revealed few existing services for men with PC across Canada, most were inclusive of multiple cancers and not tailored for men with PC. Eighteen completed studies were identified in the scoping literature review. The majority provided combined diet and exercise programs with various formats of delivery such as individual, group and home-based. Overall, $78 \%$ of studies reported improvements in one or more of the following measures: dietary intake/ diet quality, body composition, self-efficacy, quality of life, fatigue, practicing health behavior goals and physical function/ exercise. Four studies assessed feasibility, adherence or satisfaction with all reporting positive findings.

Conclusion: Despite the high prevalence of PC in Canada, and the perceived need for more support by patients and health professionals, there are limited nutrition services for men with PC. Evidence from the literature suggests nutrition services are effective and well-accepted by men with PC. Our findings define a need for standardized nutrition services for men with PC that assess and meet long term nutritional needs. Our findings also provide insight into the type and delivery of nutrition services that may help close the gap in care for men with PC.

Keywords: Nutrition services, Supportive care, Survivorship, Cancer, Prostate cancer, Diet and cancer

\section{Background}

In 2018, an estimated 1.3 million men were diagnosed with prostate cancer (PC) worldwide [1]. PC is the second most common cancer in men, and is particularly prevalent among developed countries [1]. Over the past decade there have been substantial improvements in cancer care including earlier detection, management and treatment leading to declining PC mortality and a 5-year relative survival rate of 95\% [2]. Supportive care for men with PC and their families is important since many men

\footnotetext{
* Correspondence: Rachel.murphy@ubc.ca

${ }^{1}$ School of Population and Public Health, University of British Columbia,

Vancouver, BC, Canada

Full list of author information is available at the end of the article
}

may face physical, psychological and psychosocial challenges following a PC diagnosis and therapy for sexual and urinary dysfunction, fear of cancer reoccurrence and development of other chronic diseases [3]. Due to enhanced PC care, men are more likely to die from cardiovascular or respiratory diseases, rather than from $\mathrm{PC}$ itself [4-7].

Diet also plays an important role in the prevention of chronic diseases (e.g. diabetes, cardiovascular disease and osteoporosis) that men with $\mathrm{PC}$ can be at increased risk of developing, particularly with the use of androgen deprivation therapy (ADT) which is associated with increased fat mass and insulin resistance [8-10]. For 
instance, a study of over 73,000 men with prostate cancer found those treated with ADT had a 44, 16, 11 and $16 \%$ increased risk of developing diabetes, coronary heart disease, myocardial infarction and sudden cardiac death, respectively [9]. High levels of obesity are prevalent among cancer survivors, often at similar levels as the general population [11]. Most studies also report less healthy diets among male cancer survivors, including lower fruit and vegetable intake compared to breast and uterine cancer survivors $[12,13]$. As a result, the American Cancer Society's Prostate Cancer Survivorship Care Guidelines emphasize the need for nutrition as a part of survivorship care for men with PC [3]. Furthermore, men diagnosed with $\mathrm{PC}$ may be motivated to make dietary changes after a cancer diagnosis [14]. A large body of evidence shows that lifestyle change, including dietary modifications are feasible for men with PC [15], may minimize side effects of PC treatment [4], help achieve a healthy body mass index [16-19], and improve health related quality of life [20]. Studies report that men with PC value access to dietary advice and use dietary change as a way to regain control over their diagnosis and to enhance survivorship [21, 22]. Together, this evidence highlights the importance of delivering nutrition services for men with PC to provide the knowledge and support needed to make lifestyle changes to improve quality of life and minimize the effects of PC and related treatment.

Despite the need for nutrition in supportive PC care, there are barriers to delivering nutrition services [23]. This may be particularly true in a public health care system. In Canada, many hospitals prioritize access to nutrition services due to limited funding and thus access to dietitians. For example, at many provincial cancer agencies, patients are referred to a dietitian only if they meet criteria for malnutrition which is generally based on a history of recent weight loss or if patients experience severe side effects of cancer treatment that impact dietary intake, both of which are uncommon among men with PC [24]. Several Canadian provinces operate free telephone-based services supported by provincial government that connect people with dietitians [25-28]. However, there are a limited number of dietitians with expertise in oncology and they provide services for all types of cancers (e.g. there is one oncology dietitian at HealthLink BC that serves the 4.6 million people in British Columbia (BC)).

As a result, within a public healthcare system, access to nutritional services is often limited for men with PC. Indeed, there is no standard nutrition education program for PC across BC. This, along with the evidence from the published literature, suggests there is a missed opportunity to support the needs of men with PC, and encourage lifestyle change to improve PC outcomes and overall health. New healthcare programs that draw on additional sources of funding, may be a means to provide more comprehensive support to patients. The Prostate Cancer Supportive Care (PCSC) Program [29], that includes education on lifestyle changes for diet and exercise, was established in 2013 and is now being expanded to cancer centres across $\mathrm{BC}$ in partnership with the provincial cancer agency (BC Cancer). Currently, diet and nutrition information are provided in the PCSC Program through a single group education session. However, it is unlikely that this education session alone adequately meets the needs of men with PC. An understanding of the nutritional needs of men with $\mathrm{PC}$, nutrition services available to men with $\mathrm{PC}$ in other healthcare settings and services that could be implemented from the evidence base is critical for informing supportive care delivery within the PCSC Program and supportive care programs more broadly. We conducted a needs assessment of nutritional services for men with PC that drew on four areas; 1) patient evaluation of the current PCSC nutrition education session, 2) a health professional survey regarding nutritional services, 3) an environmental scan of existing nutritional services for men with PC in Canada, and 4) a scoping literature review of nutrition services for men with PC.

\section{Methods}

Evaluation of the PCSC Program's "Nutrition for Prostate Cancer Patients" education session

To provide patients' perspectives on nutrition services, we analyzed existing patient feedback on the PCSC Program's nutrition education session. All men diagnosed with PC and their families from the greater Vancouver area were eligible to attend the session after registering with the PCSC Program. The 2-h session was delivered at Vancouver General Hospital in BC by a Registered Dietitian from BC Cancer in a lecture-style format and included time for questions and answers. The topics included nutrition and exercise guidelines for cancer survivors [3], plant-based foods, dietary patterns, obtaining nutrients from foods not supplements, Eating Well with Canada's Food Guide [30], and an overview of diet and dietary supplement intervention studies in PC [31]. Immediately after the session concludes, attendees were asked to complete an anonymous evaluation form consisting of five close-ended questions related to satisfaction and open-ended additional comments. As forms are anonymous, we did not collect demographic or clinical information from participants.

\section{BC Health professional survey}

We developed a survey to seek perspectives on the perceived need for nutrition services from health professionals in $\mathrm{BC}$ (urologists, radiation oncologists, medical 
oncologists, and registered dietitians) caring for men with PC. BC-based researchers with expertise in PCrelated nutrition research were also invited to take part. The survey consisted of six questions that asked about the importance of nutritional services for men with PC, the content of such services, and how and when these services should be delivered. The survey was developed for this research study and is presented in Additional file 1. BC Health Professional Survey Questions. The questions were pilot tested and refined for clarity before being distributed to the larger sample. Purposive sampling was used to identify 56 health professionals who were asked to complete the survey via email within a 12-week period (May 2017 to August 2017). Reminder emails were sent to encourage participation.

\section{Environmental scan of existing nutritional services for men with PC}

To understand existing nutrition services available for men with PC in Canada, we conducted an environmental scan of services. Appropriate resources were those that provided information on services of interest defined a priori as those directly related to nutrition or diet that were provided to men with PC at any point in care. This included nutrition education sessions, cooking classes, individual counselling and online or telephone services that are available to men with PC.

The predominant search strategy was to contact each of the ten provincial cancer agencies that provide cancer services for Canadians. We asked personnel at the cancer agencies to share information on other relevant nutrition services outside of their organization. Contact with identified organizations was attempted through email or telephone up to three times. This was supplemented by consulting a BC Cancer resource librarian for knowledge on existing nutrition services; and an online search using the following keywords "prostate cancer" and "nutrition" or "diet" and "services" using the Google search engine and limited results to those in English and Canadian organizations. The search was inclusive of services up to August 2019. A data collection form was used to collect information on the scope of the program, the target audience and the mode of delivery of nutrition services (available in the Additional file 1. Environmental Scan Data Collection Form).

\section{Scoping literature review}

We conducted a scoping literature review to describe best practices and research related to delivering nutritional services to men with PC including men with a history of PC and current diagnosis. The PRISMA checklist was used to define the population and guide the search and data collection strategies. A reference librarian at the University of British Columbia guided the database selection and search strategy, which relied on Embase, Medline and CINAHL electronic databases to identify relevant articles. MeSH terms and keywords included variations of the terms "prostate cancer" and "nutrition services" as detailed in the Additional file 1. We reviewed the references of articles to identify additional articles not captured by the initial search. We also searched Clinicaltrials.gov to identify ongoing and planned studies that included nutritional services.

Articles were included in the review if they met the following inclusion criteria 1) participants were men with a PC diagnosis; either exclusively or a proportion of the overall study population; 2) studied a nutrition service or an education program; 3) the service or program was provided after PC diagnosis; 4) the article was in English and 5) articles published within the past 10 years (between 2007 and 2018). Articles were excluded if there was insufficient information on the nutrition services or program that prohibited extraction of key information.

We used Mendeley referencing software version 1.17.9 to upload search results and remove duplicate articles. The primary reviewer conducted a title and abstract review of each article followed by a full text review to select articles for inclusion. A secondary reviewer repeated this process on a random $25 \%$ subset of articles. The agreement between the first and second reviewer was $97 \%$ for the title and abstract screening of articles from the initial search. The agreement was $57 \%$ for the full text screening of articles included from the title and abstract screening. Due to the discrepancy, the reviewers met in-person to re-review the screening process, discuss articles in disagreement and identify the source of the disagreements. The full text review was subsequently repeated and agreement was reached for all articles.

From each article, we abstracted summaries of key points, the type of service provided (diet and exercise; nutrition; diet and mindfulness; clinical program) or delivery of nutrition services (home-based, group education, individual counselling, other), findings and study limitations and strengths. The data abstraction form is available in the Additional file 1.

\section{Analysis}

Descriptive statistics are reported as means for continuous variables and as number and percentage for categorical variables for all four aims; patient evaluation, the health professional survey, the environmental scan and scoping literature review of nutrition services for men with PC.

Comparisons of categorical variables were performed using Chi squared tests while comparisons between continuous variables were performed with t-tests. Fisher's exact tests were performed when the assumptions for Chi squared tests were not met. Significance was 
determined at $p<0.05$. Analyses were performed with $\mathrm{R}$ version 3.4.3 (R Foundation for Statistical Computing, Vienna, Austria). Analyses specific to each study approach are described below.

\section{Evaluation of nutrition education sessions}

Questions with missing data (non-response) were excluded from the analysis $(N=3,13,45,27$, and 6 participants for questions one through five, respectively). Responses were summarized for all respondents as well as separately for patients and partners. Differences in responses between patients and partners and between patients who attended sessions with a partner versus those who attended alone were compared using chi square tests or Fisher's exact tests for yes/no questions and two sample t-tests for Likert scale questions. Open-ended questions were analyzed using deductive and realist qualitative methods [32]. Deductive analysis uses qualitative data to identify themes specifically related to the research question and a realist approach describes the experience and reality of participants as reported in the data [32]. Responses were coded as key words and organized by emerging themes that were decided and summarized based on the frequency of occurrence. Themes and the total number of responses for each theme are reported and used to provide more detail and richness to the data.

\section{BC Health professional survey}

Question three, which asked about perceived demand for nutritional support for PC patients had 1 nonresponse which was excluded from the analysis, all other questions were complete. Responses for each question were summarized as proportions and compared across professions (physicians, radiation oncologists, medical oncologists, registered dietitians and researchers). Responses between dietitians and physicians, urologists, radiation oncologists and medical oncologists together were compared with chi squared tests and fisher's exact test. Each question had the option to provide an openended response ('other, specify'). These responses were thematically analyzed in the same manner as the nutrition education session.

\section{Environmental scan and scoping review}

Information was categorized based on common themes including type of service/intervention, target audience and for the characterization of existing services; geographic region.

\section{Results}

Nutrition session evaluation

Between November 2013 and September 2016, 14 nutrition education sessions were delivered and 207 completed evaluation forms from 135 men with PC and 72 partners were collected. Evaluation responses are shown in Table 1. All participants reported that the session was easy to understand. The majority (88\%) reported that the session was an appropriate length and $87 \%$ did not feel there was any information missing from the session. When asked about the inclusion of their partners in the education session, 94\% of participants (patients, partners and patients who did not attend with a partner) agreed that inclusion was useful. Overall, $63 \%$

Table 1 Patient and partner responses to the nutrition session evaluation

\begin{tabular}{|c|c|c|c|}
\hline Participant & \multicolumn{2}{|l|}{ Response } & $p$-value \\
\hline \multicolumn{4}{|c|}{$\begin{array}{l}\text { Q1. Was the material presented in a clear fashion and easy to } \\
\text { understand? }\end{array}$} \\
\hline & Yes, N (\%) & No, N (\%) & \\
\hline Patient & $133(100)$ & 0 & \\
\hline Partner & $71(100)$ & 0 & - \\
\hline Patient with partner & $71(100)$ & 0 & \\
\hline Patient without partner & $39(100)$ & 0 & - \\
\hline \multicolumn{4}{|c|}{$\begin{array}{l}\text { Q2: Is there information you feel that was missed and should be } \\
\text { included? }\end{array}$} \\
\hline & Yes, N (\%) & No, N (\%) & \\
\hline Patient & $18(14)$ & $113(86)$ & \\
\hline Partner & $7(11)$ & $56(89)$ & 0.61 \\
\hline Patient with partner & $8(11.3)$ & $63(88.7)$ & \\
\hline Patient without partner & $8(21.6)$ & $29(78.4)$ & 0.15 \\
\hline
\end{tabular}

Q3: Would you prefer the session be longer or shorter?

$\begin{array}{llll} & \text { Yes, N (\%) } & \text { No N (\%) } & \\ \text { Patient } & 14(13) & 94(87) & \\ \text { Partner } & 6(11) & 48(89) & 0.32 \\ \text { Patient with partner } & 13(12.4) & 92(87.6) & \\ \text { Patient without partner } & 5(14.7) & 29(85.3) & -\end{array}$

Q4: Did/would you find the inclusion of partners and/or family members valuable?

$\begin{array}{llll} & \text { Yes, N (\%) } & \text { No, N (\%) } & \\ \text { Patient } & 103(92) & 9(8) & \\ \text { Partner } & 67(99) & 1(1) & - \\ \text { Patient with partner } & 128(98.5) & 2(1.5) & \\ \text { Patient without partner } & 21(72.4) & 8(27.6) & - \\ & \text { Mean rating out of 4 (SD) } & p \text {-value }\end{array}$

Q5: Overall, how beneficial did you find the session?

Patient $\quad 3.62(0.54)$

Partner $\quad 3.64(0.49)$

Patient with partner $\quad 3.70(0.55)$

Patient without partner $\quad 3.53(0.50)$

Comparisons between patients and partners and patient with partner and patient without partner for questions 1-4 with chi-square and question 5 with two-tailed $t$-test. Missing $p$-value indicates inadequate sample size for analysis 
of participants found the session very beneficial with a mean rating of $3.6(\mathrm{SD}=0.52)$ out of 4 for both patients and partners. Responses between patients and partners and between patients who attended with their partner and those who did not were similar for all questions with the exception of question four which asked if the inclusion of partners was valuable. The vast majority of patients (92\%), partners (99\%) and patients with partners (98.5\%) responded 'yes' and thus cell counts for 'no' were too few for comparison.

Thematic analysis of the qualitative data from the evaluation forms indicated a high level of satisfaction with the session. Other themes that emerged from the comments suggested that inclusion of partners was useful for processing the information presented during the session ( $n=16,30 \%$ of comments), helpful for implementing and supporting dietary changes at home $(n=$ $34,63 \%$ of respondents) or both $(n=5,9 \%)$. Comments identified perceived information gaps in the nutrition education session among $27 \%$ of respondents such as the need for more information on the role of specific dietary components (e.g. sugar, genetically modified food, animal protein, and supplements), as well as individual concerns among $12 \%$ of respondents (e.g. food sensitivities, diet for specific PC treatments), and practical meal planning tips and suggestions. Several participants $(12 \%)$ also indicated that they would like access to further nutrition services, and $5 \%$ further specified they wanted access to one-on-one dietary counselling.

\section{BC health professionals survey}

The survey was sent to 56 health professionals in $\mathrm{BC}$ including 41 physicians (urologists $(n=24)$, radiation oncologists $(n=12)$, medical oncologists $(n=5))$, registered dietitians $(n=13)$ and researchers $(n=2)$. Thirty-eight healthcare professionals responded to the survey for a response rate of $68 \%$. The questions and response rates by each profession are shown in the Additional file 1: Table S1. BC Health Professional survey response rate across professions.

The majority of health care professionals that responded (85\%) reported that men with PC have expressed nutrition related concerns to them. Over $60 \%$ of health professionals agreed that men with PC are in need of more nutritional support, $16 \%$ reported that current nutrition services are sufficient and 24\% responded with "other". Of those who responded with "other", nearly half stated they were unaware of current nutritional services for men with PC. One reported that men require specific food and nutrition skills for PC. The remaining believed there was not a high demand for nutrition information among men, that there were sufficient services but men were unaware of current programs or that nutrition support was not as critical for men with PC compared with other cancers. There were no significant difference between responses from physicians and dietitians when asked about men with PC's interest and need for nutrition services.

Most health professionals responded that nutrition services should focus on weight management $(61 \%)$ and reducing the risk of PC progression (53\%). However, there was inter-professional disagreement with respect to the focus of nutrition services - $90 \%$ of registered dietitians believed services should focus on reducing the risk of PC progression, whereas $75 \%$ of physicians believed the focus should be on weight management. The majority (67\%) responded that nutritional services should be available to men multiple times after diagnosis through consecutive group education sessions (66\%), online resources $(66 \%)$ or individual nutritional counselling with a registered dietitian (50\%). The overall themes that emerged from the open-ended questions suggested that 1) nutrition services should be available in different forms to facilitate individual needs $(n=12,34 \%)$ and 2$)$ there is a need for more nutrition services and organizational capacity to deliver services $(n=8,23 \%)$. Health professionals specified a lack of funding $(n=2$, $6 \%)$ and dietitian resources $(n=1,3 \%)$ as barriers to implementing nutrition services for men with prostate cancer. A summary of the thematic analysis is available in the Additional file 1: Table S3. Summary of themes from the health professional survey.

\section{Environmental scan of existing nutritional services for men with PC}

A total of 30 organizations that provide nutritional services across Canada were identified. Of the organizations identified, 22 provided information on their services. Six of the $22(27 \%)$ organizations offered nutritional services specifically targeted to men with PC. Of these, four offered group education sessions and three offered online services (nutrition videos and online portal with nutrition information). The PC-specific group education sessions were offered through organizations in BC $(n=2)$, Alberta $(n=1)$ and Nova Scotia $(n=1)$. The content focused on diet modifications for different PC treatments, review of diet and PC evidence and promotion of a healthy diet. Six nutritional guides for men with PC were identified through the online search, three from national agencies, two from BC Cancer and one from a cancer centre in Ontario. The remaining 16/22 organizations offered nutrition services for cancer patients including but not specific to men with PC. A variety of services such as cooking classes, group nutrition education sessions, online resources, dietitian telephone services, wellness retreat and individual counselling were available through these organizations. 


\section{Scoping review}

The literature search identified 1030 articles and interventions through databases $(n=999)$, references lists $(n=25)$ and www.clinicaltrials.gov $(n=6)$. After the title and abstract review, 33 articles and interventions were included in the final scoping review. Of these articles, 27 were primary studies while the remaining six articles were secondary analyses of the primary studies (Table 2). An exception to the inclusion criteria of publication in the last 10 years was made for four studies, two of which provided details on study design and methodology needed to assess studies captured in the search. The other two were included as they represented a significant contribution to the body of evidence that was not captured in more contemporary studies.

The majority of studies $(63 \%)$ used a randomized controlled study design $[16,18,19,33,35,36,39,40,42,45$, $47-49,51,55-59]$ while the remaining studies (22\%) used pre-post $[43,44,49,50,52,53]$, longitudinal (4\%) [38], implementation (4\%) [46], a program summary design (4\%) [60] and non-randomized control trial (4\%) [54]. The length of study interventions ranged from a single time point to 24 months. Men with PC who were treated with $\mathrm{ADT}$ or were to receive $\mathrm{ADT}$ were the most common population (55\%) [19, 38, 39, 43, 44, 47-51, 55, 57] followed by men post PC diagnosis (30\%) [42, 43, 45, $46,56,60]$, and different cancer types including men with PC $(15 \%)[33,35,36]$. The majority $(52 \%)$ of interventions were combined diet and exercise programs [19, $33,35,36,38-40,43,48,50,51,55,57,60]$. Six (22\%) $[42,44,47,48]$ exclusively provided nutritional services, while the remaining (18\%) offered nutritional services as part of a comprehensive clinical program [46, 49], diet and mindfulness services (4\%) [43], or diet, mindfulness and exercise services (4\%) [45]. The format in which services were delivered included individual nutritional counselling (33\%) [43, 47-51,56], group education sessions (33\%) [39, 40, 42, 44, 46, 55], both individual and group sessions $(7 \%)[43,45]$, home-based services $(22 \%)$ such as mailed educational material [19, 35, 36, 38, 40], and multiple forms of delivery (4\%) including classes, home-based and individual counselling [60]. Additional details of the studies identified can be found in Table 3 .

Of the 27 studies identified in the review, 18 were complete and had published their findings (Table 2). The remaining nine studies were in progress at the time of the literature review. Of the completed studies, $78 \%$ reported improvements in one or more of the following measures: dietary intake/ diet quality, body composition, self-efficacy, quality of life, fatigue, practicing health behaviour goals and physical function/ exercise. Christry et al. was the only study that measured the long-term impact of nutrition services and found sustained improvements in diet quality, energy intake, and saturated fat intake 2 years following a 10-month home-based diet and exercise intervention [17]. All studies that examined qualitative outcomes $(n=4)$ such as feasibility, adherence and participant satisfaction, reported positive findings [38, 40, 46, 49]. Common facilitators of dietary behavior change and/or patient satisfaction were group education $[1,42]$ and peer support $[46,59]$. Other studies emphasized the importance of individualized nutrition services $[9,50,52]$. Common limitations included the use of self-reported measures, healthy participant bias, small sample size, short follow up period and lack of generalizability to the overall PC population. Our interpretation was limited by studies of participants with various cancer types (e.g. breast, colorectal, prostate) that did not provide cancer-specific results. This limits our understanding of the effect of these interventions on men with PC.

\section{Discussion}

To our knowledge this is the first report to provide a multifaceted approach to capture the need for nutritional services focused on men with PC. This approach is critical for informing and delivering evidence-based health services. Findings from multiple perspectives suggest that men with PC have an unmet need for nutritional information during supportive care. For instance, a need for additional nutrition services and support was identified by respondents to the $\mathrm{BC}$ health professional survey, few services for men with PC exist and even among those with access to nutrition education, there was indication of wanting more support. However, findings also indicate that survivorship clinics and cancer care centres vary widely in the range of nutritional services provided to men with $\mathrm{PC}$, and few are specific to PC. Although generally, nutrition interventions were effective, nutrition interventions for men with PC published in the literature are heterogeneous with respect to design, mode of delivery and content, making it difficult to identify best practices. Standardized approaches would facilitate discovery and potentially implementation of effective PC care, however, the complexity of such an undertaking would be substantial.

Each of the four approaches taken in this study provided important findings that can inform supportive care programming. The evaluation forms from the nutrition education session demonstrated overall high satisfaction with the PCSC Program's existing in-person groupbased educational session. Together with the qualitative feedback expressing a desire for more nutrition related information, this demonstrates a patient-perceived need for nutrition services among men with PC. A previous study among recently treated men with $\mathrm{PC}$ also reported group education on general PC knowledge including nutrition was well accepted and resulted in increased 
Table 2 Studies identified in the nutrition services scoping review

\begin{tabular}{llllll}
\hline Author & $\begin{array}{l}\text { Mode of } \\
\text { nutrition } \\
\text { services }\end{array}$ & $\begin{array}{l}\text { Focus of } \\
\text { nutrition } \\
\text { services }\end{array}$ & Design & Aim & Key Findings \\
\hline $\begin{array}{l}\text { Demark- } \\
\text { Wahnefried } \\
{[16,33]}\end{array}$ & $\begin{array}{l}\text { Home- } \\
\text { based }\end{array}$ & $\begin{array}{l}\text { Diet and } \\
\text { exercise }\end{array}$ & RCT & $\begin{array}{l}\text { To determine if custom exercise and } \\
\text { nutrition print material is effective in } \\
\text { promoting lifestyle changes for people } \\
\text { living with breast or prostate cancer. }\end{array}$ & $\begin{array}{l}\text { The FRESH START intervention arm } \\
\text { demonstrated significant improvement } \\
\text { in practicing goals, exercise, dietary } \\
\text { intake and BMl compared to the control. }\end{array}$ \\
Christy [17] & $\begin{array}{l}\text { Home- } \\
\text { based/ } \\
\text { Individual } \\
\text { counselling }\end{array}$ & $\begin{array}{l}\text { Diet and } \\
\text { exercise }\end{array}$ & RCT & START trial 2 years post baseline. & $\begin{array}{l}\text { The intervention arm sustained } \\
\text { significant improvements in dietary } \\
\text { intake and diet quality compared to the } \\
\text { control. }\end{array}$
\end{tabular}

\begin{tabular}{|c|c|c|}
\hline $\begin{array}{l}\text { Mosher [33, } \\
34]\end{array}$ & Mail & $\begin{array}{l}\text { Diet and } \\
\text { exercise }\end{array}$ \\
\hline $\begin{array}{l}\text { Morey [18] \& } \\
\text { Snyder [35] }\end{array}$ & $\begin{array}{l}\text { Home- } \\
\text { based }\end{array}$ & $\begin{array}{l}\text { Diet and } \\
\text { exercise }\end{array}$ \\
\hline
\end{tabular}

o examine changes in self-efficacy as a mediator of the FRESH START intervention.

To determine if home-based multibehaviour interventions can improve functional decline in older cancer survivors.

$\begin{array}{llll}\begin{array}{l}\text { Demark- } \\ \text { Wahnefried } \\ {[36,37]}\end{array} & \begin{array}{l}\text { Home- } \\ \text { based }\end{array} & \begin{array}{l}\text { Diet and } \\ \text { exercise }\end{array} & \text { RCT } \\ \text { Lebret }[38] & \begin{array}{l}\text { Home- } \\ \text { based }\end{array} & \begin{array}{l}\text { Diet and } \\ \text { exercise }\end{array} & \begin{array}{l}\text { Longitudinal } \\ \text { survey }\end{array}\end{array}$

O'Neil [19] $\begin{array}{lll}\text { Home- } & \text { Diet and } \\ \text { based } & \text { RCercise }\end{array}$

Bourke [39] Group Diet and education exercise

$\begin{array}{llll}\text { Bourke [40] } & \begin{array}{l}\text { Group } \\ \text { education }\end{array} & \begin{array}{l}\text { Diet and } \\ \text { exercise }\end{array} & \text { RCT } \\ \text { Bourke [41] } & \begin{array}{l}\text { Group } \\ \text { education }\end{array} & \begin{array}{l}\text { Diet and } \\ \text { exercise }\end{array} & \text { RCT }\end{array}$

$\begin{array}{llll}\text { Carmody [42] } & \begin{array}{l}\text { Group } \\ \text { education }\end{array} & \text { Diet } & \text { RCT } \\ \text { Nguyen [43] } & \begin{array}{l}\text { Group } \\ \text { education/ } \\ \text { Individual } \\ \text { counselling }\end{array} & \begin{array}{l}\text { Diet and } \\ \text { mindfulness }\end{array} & \text { Pre-post } \\ \text { Davison [44] } & \begin{array}{l}\text { Group } \\ \text { education }\end{array} & \text { Diet } & \text { Pre-post }\end{array}$

To determine if a home-based diet and exercise intervention can improve physical functioning in older adults with breast and prostate cancer.

To assess the use of a diet and exercise tool-kit in improving well-being for men with PC on ADT.

To assess if a home-based diet and exercise intervention can help minimize side effects of ADT for men with PC.

To assess the effect of lifestyle interventions on QoL, diastolic blood pressure and fatigue in men with PC on ADT.

To assess the feasibility of a tapered supervised exercise and diet intervention for men with PC on ADT.

To qualitatively evaluate tapered exercise and diet intervention for men with PC on ADT.

To assess if dietary interventions can improve dietary intake, QoL and PSA velocity in men with $P C$

To measure changes in dietary intake and PSA velocity following a dietary and stress reduction intervention in men with recurrent $\mathrm{PC}$.

To measure the impact of a nutrition intervention on calcium and vitamin D intake for men with PC on ADT.

To assess the effects of lifestyle interventions on PSA levels and reducing
Changes in self-efficacy significantly mediated the effect of the intervention on dietary outcomes.

The intervention arm had a significant reduction in the rate of functional decline and improvements in physical activity, dietary behaviours and overall quality of life.

At 6 months the intervention group improved diet quality and self-efficacy to exercise but these changes were not maintained post intervention.

The majority of patients and urologists reported satisfaction with the tool-kit and the majority of patients reported implementing guidelines from the toolkit.

At 6 months the intervention arm demonstrated significant improvements in body composition, dietary intake, functional capacity but not fatigue, stress or QoL.

At completion the intervention arm had significant improvements in QoL, fatigue and exercise tolerance however only improvements in fatigue, exercise tolerance were sustained at 6 months.

The intervention arm showed significant improvements in dietary intake, exercise, and fatigue however there were high attrition rates at 6 months.

Participants reported benefiting from the intervention both physically and psychologically. Participants reported benefits from dietary education but found adherence to guidelines difficult.

The intervention arm demonstrated improvements in diet quality/ intake and QoL. No significant changes were observed for PSA velocity.

Following the intervention the participants significantly improved dietary intake however no significant reductions in PSA rise were observed.

Following the intervention there were no significant increases in calcium and vitamin D through dietary intake however there were significant increases in through supplement intake.

The intervention arm did not show any significant changes in PSA levels 
Table 2 Studies identified in the nutrition services scoping review (Continued)

\begin{tabular}{|c|c|c|c|c|}
\hline Author & $\begin{array}{l}\text { Mode of } \\
\text { nutrition } \\
\text { services }\end{array}$ & $\begin{array}{l}\text { Focus of } \\
\text { nutrition } \\
\text { services }\end{array}$ & Design & Aim \\
\hline & $\begin{array}{l}\text { Individual } \\
\text { counselling }\end{array}$ & $\begin{array}{l}\text { and } \\
\text { mindfulness }\end{array}$ & & the risk of $P C$ recurrence. \\
\hline $\begin{array}{l}\text { Ferguson } \\
{[46]}\end{array}$ & $\begin{array}{l}\text { Group } \\
\text { education }\end{array}$ & $\begin{array}{l}\text { Comprehensive } \\
\text { program }\end{array}$ & $\begin{array}{l}\text { Implementation } \\
\text { study }\end{array}$ & $\begin{array}{l}\text { To evaluate the implementation and } \\
\text { early impact of a nurse-led survivorship } \\
\text { program for men with PC. }\end{array}$ \\
\hline Baguley [47] & $\begin{array}{l}\text { Individual } \\
\text { counselling }\end{array}$ & Diet & RCT & $\begin{array}{l}\text { To assess the efficacy of a } \\
\text { Mediterranean-style nutrition interven- } \\
\text { tion on cancer related fatigue and QoL } \\
\text { in men with PC on ADT. }\end{array}$ \\
\hline Baguley [48] & $\begin{array}{l}\text { Individual } \\
\text { counselling }\end{array}$ & $\begin{array}{l}\text { Diet and } \\
\text { exercise }\end{array}$ & $\mathrm{RCT}$ & $\begin{array}{l}\text { To assess the efficacy of high intensity } \\
\text { interval training in addition nutrition } \\
\text { therapy on cancer related fatigue in men } \\
\text { with PC on ADT. }\end{array}$ \\
\hline $\begin{array}{l}\text { Aggarwal } \\
\text { [49] }\end{array}$ & $\begin{array}{l}\text { Individual } \\
\text { counselling }\end{array}$ & $\begin{array}{l}\text { Comprehensive } \\
\text { program }\end{array}$ & Pre-post & $\begin{array}{l}\text { To assess the adherence to a } \\
\text { multidisciplinary clinic for men with PC } \\
\text { on ADT and if the intervention can } \\
\text { lessen the metabolic impacts of ADT. }\end{array}$ \\
\hline Joly [50] & $\begin{array}{l}\text { Individual } \\
\text { counselling }\end{array}$ & $\begin{array}{l}\text { Diet and } \\
\text { exercise }\end{array}$ & Pre-post & $\begin{array}{l}\text { To assess the impact of a nutrition and } \\
\text { exercise intervention on body } \\
\text { composition and physical function in } \\
\text { frail men with PC on ADT. }\end{array}$ \\
\hline Focht [51] & $\begin{array}{l}\text { Individual } \\
\text { counselling }\end{array}$ & $\begin{array}{l}\text { Diet and } \\
\text { exercise }\end{array}$ & RCT & $\begin{array}{l}\text { To assess the feasibility and preliminary } \\
\text { efficacy of implementing a group- } \\
\text { mediated cognitive behavioural lifestyle } \\
\text { intervention for men with PC undergo- } \\
\text { ing ADT. }\end{array}$ \\
\hline
\end{tabular}

$\begin{array}{llll}\text { Chan [46] } & \text { Other } & \begin{array}{l}\text { Diet and } \\ \text { exercise }\end{array} & \begin{array}{l}\text { Program } \\ \text { summary }\end{array} \\ \text { Cosby [52] } & \begin{array}{l}\text { Group } \\ \text { education }\end{array} & \text { Diet } & \text { Pre-post }\end{array}$

The purpose of TrueNTH is to create an international partnership and develop interventions to improve the physical and mental well being of PC survivors.

Key Findings

however they did demonstrate significant improvements in dietary intake.

The program had high participation rates with $90 \%$ attendance. Feedback from participants suggests high user satisfaction and reported QoL improvement.

Improvements in QoL and fatigue were not significant, however the intervention arm did demonstrate significant changes in weight.

N/A

Participation and adherence to the clinic was high with $95 \%$ adherence. The metabolic impact of ADT was minimal during the intervention.

After 3 months of ADT participants had improved timed-up-and-go test while other measures of physical function and body composition remained stable.

N/A

To evaluate the effectiveness and satisfaction of a weekly diet and PC group education session on meeting information needs in promoting healthy body weights.

Golubić [53] Group education

Comprehensive Pre-post program

To evaluate the effectiveness of Lifestyle 180, a comprehensive, lifestyle program, on chronic disease risk factors and QOL in cancer survivors.

$\begin{array}{ll}\text { Takada [54] } & \text { Group } \\ & \text { education }\end{array}$

Diet

Ongoing clinical trials:

$\begin{array}{llll}\text { Goulart [55] } & \begin{array}{l}\text { Group } \\ \text { education }\end{array} & \begin{array}{l}\text { Diet and } \\ \text { exercise }\end{array} & \text { RCT }\end{array}$

Kellogg Individual Diet

Parsons [56] counselling
To evaluated the efficacy of nutrition education on changes in daily rectal volume and dose during IMRT treatment.

To evaluate the multidisciplinary Living Well on Androgen Deprivation Therapy program on QoL, physical factors and biomarkers of secondary diseases in men with PC on ADT.

To assess the impact of a telephone based dietary intervention on disease progression in men with PC on active surveillance.
Canada, the U.S.A, Australia and the U.K. are developing lifestyle interventions and programs for men with PC and will evaluate implementation approaches.

Significantly improved nutrition knowledge post session. Participants reported high satisfaction rates, usefulness of information, the importance of information and the value of group learning.

Significant improvements in weight loss and WC, BMI and measured biomarker. Reported reduction in lipid lowering and BP medication. Reported improvements in perceived stress and QOL.

Patients who attended the nutrition education session had decreased variations in rectal volume and treatment dose compared to controls resulting in more reproducible results.

N/A

N/A 
Table 2 Studies identified in the nutrition services scoping review (Continued)

\begin{tabular}{|c|c|c|c|c|c|}
\hline Author & $\begin{array}{l}\text { Mode of } \\
\text { nutrition } \\
\text { services }\end{array}$ & $\begin{array}{l}\text { Focus of } \\
\text { nutrition } \\
\text { services }\end{array}$ & Design & Aim & Key Findings \\
\hline McArdle [57] & $\begin{array}{l}\text { Individual } \\
\text { counselling }\end{array}$ & $\begin{array}{l}\text { Diet and } \\
\text { exercise }\end{array}$ & $\mathrm{RCT}$ & $\begin{array}{l}\text { To assess the feasibility of a nutrition } \\
\text { and exercise counselling intervention on } \\
\text { reducing the incidence of metabolic } \\
\text { syndrome in men with PC on ADT. }\end{array}$ & N/A \\
\hline Maliski [58] & $\begin{array}{l}\text { Individual } \\
\text { counselling }\end{array}$ & $\begin{array}{l}\text { Diet and } \\
\text { exercise }\end{array}$ & RCT & $\begin{array}{l}\text { To assess if counselling on lifestyle } \\
\text { changes in addition to standard medical } \\
\text { care can prevent heart problems and } \\
\text { diabetes in men with PC on ADT. }\end{array}$ & N/A \\
\hline Lee [59] & $\begin{array}{l}\text { Home- } \\
\text { based }\end{array}$ & $\begin{array}{l}\text { Comprehensive } \\
\text { program }\end{array}$ & $\mathrm{RCT}$ & $\begin{array}{l}\text { To assess if the efficacy of a web and } \\
\text { mobile based lifestyle intervention on } \\
\text { physical function, strength, body } \\
\text { composition and QoL. }\end{array}$ & N/A \\
\hline $\begin{array}{l}\text { Aggarwal } \\
\text { [49] }\end{array}$ & $\begin{array}{l}\text { Individual } \\
\text { counselling }\end{array}$ & $\begin{array}{l}\text { Comprehensive } \\
\text { program }\end{array}$ & $\mathrm{RCT}$ & $\begin{array}{l}\text { To assess if individualized counselling } \\
\text { helps improve patient understanding, } \\
\text { satisfaction, quality of life and } \\
\text { anthropometrics. }\end{array}$ & \\
\hline
\end{tabular}

Abbreviations: $A D T$ Androgen deprivation therapy, NRCT Non-randomized controlled trial, $Q O L$ Quality of life, $R C T$ Randomized, controlled trial, $P C$ Prostate cancer, WC Waist circumference, BP Blood pressure, IMRT Intensity-modulated radiotherapy. Grey shading indicates secondary analysis of a study that was also captured in the scoping review and were therefore not considered when calculating the type and focus of interventions

knowledge [61]. Limitations to the group-based format included the need for more personalized and additional nutrition information. The need for more information is echoed in the literature including a study by Taylor et al. [62] that reported more than $50 \%$ of cancer patients would like more information on managing illness. However,

Table 3 Summary of studies identified in scoping review

\begin{tabular}{lll}
\hline Study characteristics & Number (N) & Proportion (\%) \\
\hline Design & 17 & 63 \\
RCT & 6 & 22 \\
Pre-post & 4 & 15 \\
Other & & \\
Mode of nutrition service & 9 & 33 \\
Group education & 9 & 33 \\
Individual counselling & 6 & 22 \\
Home-based & 2 & 7 \\
Group / individual counselling & 1 & 4 \\
Other & & \\
Focus of intervention & 14 & 52 \\
Diet and exercise & 6 & 22 \\
Diet & 5 & 18 \\
Comprehensive program & 1 & 4 \\
Diet, mindfulness and exercise & 1 & 4 \\
Diet and mindfulness & 8 & 30 \\
Population & 4 & \\
Men with PC treated with ADT & 15 & \\
Men with PC & & \\
Cancer patients & & \\
\hline
\end{tabular}

providing additional nutrition supportive care for men with PC within a public healthcare setting is a challenge, especially given this requires a proactive versus reactive approach as patients generally are not malnourished. Findings from the other perspectives studied herein may provide direction moving forward.

The findings from the $\mathrm{BC}$ health professional survey aligns with a comprehensive review of educational needs of cancer patients by Rutten et al. [63] who reported that cancer-specific and treatment-related information (of which nutrition is relevant to both) was required continually from diagnosis, treatment and post-treatment. Of note, there were differences between professions with respect to the content of nutrition services. Dietitians indicated that information should focus on the role of diet to reduce the risk of PC progression while medical oncologists, radiation oncologists and urologists believed that diet for weight management was the most important topic. We speculate that the differences in opinion may reflect questions commonly posed to dietitians by patients which is supported by the qualitative feedback on the nutrition evaluation session that requested more information on different dietary components and prostate cancer and notably there was no mention of more information for weight maintenance purposes. The focus on weight management by oncologists and urologists may reflect the relevance of weight management in clinical practice since increased body weight is linked to an increased risk of future prostate cancer mortality in those who are cancer free and increased risk of biochemical relapse after primary therapy $[64,65]$. In addition, increased weight gain is a known side effect of ADT that can be associated with metabolic syndrome 
and have downstream adverse effects on health [66]. Further work is needed to understand the differing perspectives in health professional disciplines to support the development of need-driven nutrition services.

Meeting the nutritional needs of men with PC in a busy healthcare setting is a challenge that is likely reflected by the small number of existing services specific to $\mathrm{PC}$ in organizations across Canada. Among the six we identified, four were in-person group education sessions. Group education has been shown to be an effective means of delivering health information in a comparable and potentially more efficient and cost-effective manner than individual education $[67,68]$. However, inperson sessions may pose accessibility problems due to geographic and logistical barriers. The remaining two organizations provided nutrition services online, which has potential to provide supportive care to a larger number of men with PC and to overcome barriers to access. Although the efficacy of the online services was not assessed, literature suggests telemedicine education can be equally effective as in person education [69]. Between 2028 and 2032, the number of new cases of PC is projected to almost double in Canada [70]. The impact on healthcare services for the growing number of men living with PC will be substantial. Alternative modes of delivery of patient information will therefore be critical.

The scoping review identified three main methods of delivering nutrition services to men with PC; homebased services, individual counselling, and group education classes. This substantiated what healthcare professionals in our survey considered the best modes of delivery, suggesting supportive care programs should consider offering flexible formats for nutrition services when possible. Although this paper is focussed on nutrition, diet is just one part of a healthy lifestyle. The generally positive findings reported by studies in the review such as feasibility, adherence and user satisfaction were not specific to the dietary component. Thus, we suggest that supportive care programs offer comprehensive healthy lifestyle services including nutrition. It is also important to highlight the difficulty in identifying 'best practice' and comparative success of approaches from the literature to inform nutrition services as studies were heterogeneous in design, target population and in primary outcome. Unsurprisingly, existing nutrition services identified in this study generally did not reflect interventions reported in literature, nor the perspectives of health care professionals with respect to content and timing of services. This confirms the well documented gap between research and practice [71].

There are several limitations to our study. Patient perspectives on nutritional services were assessed from data already collected through the PCSC programs education session evaluation form that was not designed to assess perspectives on broader nutrition services. The form also did not collect demographic information as the purpose is quality improvement and not research. Therefore, participants who attended the nutrition education session may not be representative of the general PC population. Patient engagement through focus groups and surveys would provide a deeper understanding of nutritional needs. The survey of health professionals used purposive expert sampling to capture insight on nutrition services from those working directly in PC-based healthcare or research in BC. Questions were developed by the researchers and not validated. This approach was used as our aim was exploratory in nature and required a focus on individuals with expertise providing care for men with PC. However, it also introduces researcher bias and a non-representative sample as it was confined to BC. One of the strengths of our study was the use of a multi-faceted approach that considered patient and health care perspectives, existing services and the evidence base on nutrition and PC. Incorporation of each of these areas is key for sustainable, effective nutrition services, and supportive care services more broadly.

\section{Conclusion}

As evident from the environmental scan, there are limited nutritional services targeted to the PC population despite the high prevalence of PC in Canada, and the effectiveness of nutritional services. It is perhaps unsurprising then that men with $\mathrm{PC}$ and $\mathrm{PC}$-healthcare professionals identified a need for more nutrition services. Nutrition services should consider flexibility in delivery format, support at multiple times throughout survivorship, as well as embedding nutrition as part of overall supportive care. The provision of such support will be a challenge within a public healthcare system where nutrition services are generally prioritized for those who are malnourished, which is uncommon among men with PC. New models of care with supplemental funding may help to close the gap between the needs of men with PC and current standard of care.

\section{Supplementary information}

Supplementary information accompanies this paper at https://doi.org/10. 1186/s12937-019-0506-7.

Additional file 1. BC Health Professional Survey Questions. Environmental Scan Data Collection Form. Supplementary Table 1: BC Health Professional survey response rate across professions. Supplementary Table 2: Scoping Literature Review search strategy. Supplementary Table 3: Summary of themes from the health professional survey.

\section{Abbreviations}

ADT: Androgen Deprivation Therapy; BC: British Columbia; BCCA: British Columbia Cancer Agency; PC: Prostate Cancer; PCSC: Prostate Cancer Supportive Care; VGH: Vancouver General Hospital 


\section{Acknowledgements}

We thank Ursula Ellis for her advice regarding the scoping literature review. Ursula Ellis is a Reference Librarian at the University of British Columbia, Vancouver, British Columbia, Canada.

\section{Authors' contributions}

KM made substantial contributions to the acquisition of data, analysis and interpretation of data and manuscript draft. LH contributed to the conception and research design, acquisition and analysis of data and was involved in critical revisions of the manuscript. PP contributed to the conception and research design and was involved in critical revisions of the manuscript. CH provided critical revision of the manuscript. RAM made contributions to the conception and research design and made a substantial contribution to the manuscript draft. All authors gave final approval of the manuscript to be published.

\section{Funding}

Dr. Murphy is supported by the Canadian Cancer Society (grant \#704735) and the Michael Smith Foundation for Health Research (\#17644).

\section{Availability of data and materials}

Data generated or analyzed during this study are included within the article and its supplementary information files.

\section{Ethics approval and consent to participate}

Ethics approval was not required for this research as information was obtained for the purpose of quality assurance within the PCSC Program.

\section{Consent for publication}

Not applicable.

\section{Competing interests}

The authors certify that they have NO affiliations or involvement in any organization or entity with any financial interest (such as honoraria; educational grants; participation in speakers' bureaus; membership, employment, consultancies, stock ownership, or other equity interest; and expert testimony or patent-licensing arrangements), or non-financial interest (such as personal or professional relationships, affiliations, knowledge or beliefs) in the subject matter or materials discussed in this manuscript.

\section{Author details}

${ }^{1}$ School of Population and Public Health, University of British Columbia, Vancouver, BC, Canada. ${ }^{2}$ Centre for Clinical Epidemiology and Evaluation, University of British Columbia, Vancouver, BC, Canada. ${ }^{3}$ Vancouver Prostate Centre, Vancouver, BC, Canada. ${ }^{4}$ Department of Urologic Sciences, University of British Columbia, Vancouver, BC, Canada. ${ }^{5}$ University of Washington, Fred Hutchinson Cancer Research, Seattle, WA, USA.

Received: 5 February 2019 Accepted: 18 November 2019

Published online: 02 December 2019

\section{References}

1. International Agency for Research on Cancer. Latest global cancer data: Cancer burden rises to 18.1 million new cases and 9.6 million cancer deaths in 2018. https://www.iarc.fr/wp-content/uploads/2018/09/pr263_E.pdf Accessed 6 Jan 2019.

2. Canadian Cancer Society. Prostate Cancer Statistics. 2017 http://www.cancer. ca/en/cancer-information/cancer-type/prostate/statistics/?region=bc. Accessed 4 May 2017.

3. Skolarus TA, Wolf AM, Erb NL, Brooks DD, Rivers BM, Underwood W, et al. American Cancer Society prostate cancer survivorship care guidelines. CA Cancer J Clin. 2014;64:225-49.

4. van Leeuwen PJ, Otto SJ, Kranse R, Roobol MJ, Bul M, Zhu X, et al. Increased non-prostate cancer death risk in clinically diagnosed prostate cancer. BJU Int. 2012:110:188-94

5. Epstein MM, Edgren G, Rider JR, Mucci LA, Adami HO. Temporal trends in cause of death among Swedish and US men with prostate cancer. J Natl Cancer Inst. 2012;104:1335-42.

6. Tendulkar RD, Hunter GK, Reddy CA, Stephans KL, Ciezki JP, Stephenson AJ, et al. Mortality in men treated with radiation therapy and androgen deprivation for high-risk prostate Cancer in the modern era is driven by non-prostate Cancer deaths. Int J Radiat Oncol. 2012;84:S94-5.

7. Kobayashi T, Kamba T, Terada N, Yamasaki T, Ikeda I, Inokuchi H, et al. Nonprostate cancer death within 5 years after radical therapy in men with localized prostate cancer. Washington, DC. Philadelphia (PA): Proceedings of the 104th Annual Meeting of the American Association for Cancer Research; 2013. AACR.73:Abstract nr 4677

8. Morote J, Morin JP, Orsola A, Abascal JM, Salvador C, Trilla E, et al. Prevalence of osteoporosis during long-term androgen deprivation therapy in patients with prostate cancer. Urology. 2007;69:500-4.

9. Keating NL, O'Malley A, Freedland SJ, Smith MR. Diabetes and cardiovascular disease during androgen deprivation therapy: observational study of veterans with prostate cancer. J Natl Cancer Inst. 2012;104:1518-23.

10. Tsai HK, D'Amico AV, Sadetsky N, Chen MH, Carroll PR. Androgen deprivation therapy for localized prostate cancer and the risk of cardiovascular mortality. J Natl Cancer Inst. 2007;99:1516-24.

11. Pinto BM, Trunzo JJ. Health behaviors during and after a cancer diagnosis. Cancer. 2005;104(11 Suppl):2614-23.

12. Blanchard CM, Courneya KS, Stein K. Cancer survivors' adherence to lifestyle behavior recommendations and assocations with health-related quality of life: results from the American Cancer Society's SCS-II. J Clin Oncol. 2008;26:2198-204.

13. Demark-Wahnefried W, Peterson B, McBride C, Lipkus I, Clipp E. Current health behaviors and readiness to pursue life-style changes among men and women diagnosed with early stage prostate and breast carcinomas. Cancer. 2000;88:674-84.

14. Demark-Wahnefried W, Aziz NM, Rowland JH, Pinto BM. Riding the crest of the teachable moment: promoting long-term health after the diagnosis of cancer. J Clin Oncol. 2005;23:5814-30.

15. Parsons JK, Newman V, Mohler JL, Pierce JP, Paskett E, Marshall J, Cancer, Leukemia Group B. The Men's eating and Living (MEAL) study: a Cancer and leukemia group B pilot trial of dietary intervention for the treatment of prostate cancer. Urology. 2008;72:633-7.

16. Demark-Wahnefried W, Clipp EC, Lipkus IM, Lobach D, Snyder DC, Sloane R, Peterson B, Macri JM, Rock CL, McBride CM, Kraus WE. Main outcomes of the FRESH START trial: a sequentially tailored, diet and exercise mailed print intervention among breast and prostate cancer survivors. J Clin Oncol. 2007; 25:2709-18.

17. Christy SM, Mosher CE, Sloane R, Snyder DC, Lobach DF, Demark-Wahnefried W. Long-term dietary outcomes of the FRESH START intervention for breast and prostate cancer survivors. J Am Diet Assoc. 2011;111:1844-51.

18. Morey MC, Snyder DC, Sloane R, Cohen HJ, Peterson B, Hartman TJ, Miller P, Mitchell DC, Demark-Wahnefried W. Effects of home-based diet and exercise on functional outcomes among older, overweight long-term cancer survivors: RENEW: a randomized controlled trial. JAMA. 2009;301:1883-91.

19. O'Neill RF, Haseen F, Murray LJ, O'Sullivan JM, Cantwell MM. A randomised controlled trial to evaluate the efficacy of a 6-month dietary and physical activity intervention for patients receiving androgen deprivation therapy for prostate cancer. J Cancer Surviv. 2015;9:431-40.

20. Mosher CE, Sloane R, Morey MC, Snyder DC, Cohen HJ, Miller PE, DemarkWahnefried W. Associations between lifestyle factors and quality of life among older long-term breast, prostate, and colorectal cancer survivors. Cancer. 2009;115:4001-9.

21. Avery KN, Donovan JL, Horwood J, Neal DE, Hamdy FC, Parker C, Wade J, Lane A. The importance of dietary change for men diagnosed with and at risk of prostate cancer: a multi-Centre interview study with men, their partners and health professionals. BMC Fam Pract. 2014;15:81.

22. Mroz LW, Chapman GE, Oliffe JL, Bottorff JL. Men, food, and prostate cancer: gender influences on men's diets. Am J Mens Health. 2011;5:177-87.

23. Kushner RF. Barriers to providing nutrition counseling by physicians: a survey of primary care practitioners. Prev Med. 1995;24:546-52.

24. Hebuterne X, Lemarie E, Michallet M, de Montreuil CB, Schneider SM, Goldwasser F. Prevalence of malnutrition and current use of nutrition support in patients with cancer. JPEN J Parenter Enteral Nutr. 2014;38:196-204.

25. 811 HealthLine. Newfoundland Labrador. http://www.yourhealthline.ca. Accessed 10 June 2018.

26. Get medical advice: Telehealth Ontario. Ontario. https://www.ontario.ca/ page/get-medical-advice-telehealth-ontario. Accessed 21 June 2018.

27. Health, Seniors and Active Living. Dial-a-Dietitian. Manitoba, http://www.gov. mb.ca/health/primarycare/chronicdisease/dad.html. Accessed 21 June 2018.

28. HealthLink BC Healthy Eating. https://www.healthlinkbc.ca/healthy-eating. Accessed 21 June 2018. 
29. Hedden L, Wassersug R, Mahovlich S, Pollock P, Sundar M, Bell RH, Goldenberg L, Higano CS. Evaluating an educational intervention to alleviate distress amongst men with newly diagnosed prostate cancer and their partners. BJU Int. 2017;120:E21-9.

30. Eating Well with Canada's Food Guide. Health Canada. http://www.hc-sc.gc. ca/fn-an/food-guide-aliment/index-eng.php. Accessed 26 April 2017.

31. A Nutrition Guide for Men with Prostate Cancer. BC Cancer Agency. Second Edition, July 2014. ISBN-10 1-896624-24-3.

32. Braun V, Clarke V. Using thematic analysis in psychology. Qual Res Psychol. 2006;3:77-101.

33. Demark-Wahnefried W, Clipp EC, McBride C, Lobach DF, Lipkus I, Peterson B, Clutter Snyder D, Sloane R, Arbanas J, Kraus WE. Design of FRESH START: a randomized trial of exercise and diet among cancer survivors. Med Sci Sports Exerc. 2003;35:415-24.

34. Mosher CE, Fuemmeler BF, Sloane R, Kraus WE, Lobach DF, Snyder DC, Demark-Wahnefried W. Change in self-efficacy partially mediates the effects of the FRESH START intervention on cancer survivors' dietary outcomes. Psychooncology. 2008;17:1014-23.

35. Snyder DC, Morey MC, Sloane R, Stull V, Cohen HJ, Peterson B, Pieper C, Hartman TJ, Miller PE, Mitchell DC, Demark-Wahnefried W. Reach out to ENhancE wellness in older Cancer survivors (RENEW): design, methods and recruitment challenges of a home-based exercise and diet intervention to improve physical function among long-term survivors of breast, prostate, and colorectal cancer. Psychooncology. 2009;18:429-39.

36. Demark-Wahnefried W, Morey MC, Clipp EC, Pieper CF, Snyder DC, Sloane R, Cohen $\mathrm{HJ}$. Leading the way in exercise and diet (project LEAD): intervening to improve function among older breast and prostate cancer survivors. Control Clin Trials. 2003;24:206-23.

37. Demark-Wahnefried W, Clipp EC, Morey MC, Pieper CF, Sloane R, Snyder DC, Cohen HJ. Lifestyle intervention development study to improve physical function in older adults with cancer: outcomes from project LEAD. J Clin Oncol. 2006;24:3465-73.

38. Lebret T, Coloby P, Descotes JL, Droupy S, Geraud M, Tombal B. Educational tool-kit on diet and exercise: survey of prostate cancer patients about to receive androgen deprivation therapy. Urology. 2010;76:1434-9.

39. Bourke L, Gilbert S, Hooper R, Steed LA, Joshi M, Catto JW, Saxton JM, Rosario DJ. Lifestyle changes for improving disease-specific quality of life in sedentary men on long-term androgen-deprivation therapy for advanced prostate cancer: a randomised controlled trial. Eur Urol. 2014;65:865-72.

40. Bourke L, Doll H, Crank H, Daley A, Rosario D, Saxton JM. Lifestyle intervention in men with advanced prostate cancer receiving androgen suppression therapy: a feasibility study. Cancer Epidemiol Biomark Prev. 2011;20:647-57.

41. Bourke L, Sohanpal R, Nanton V, Crank H, Rosario DJ, Saxton JM. A qualitative study evaluating experiences of a lifestyle intervention in men with prostate cancer undergoing androgen suppression therapy. Trials. 2012;13:208.

42. Carmody J, Olendzki B, Reed G, Andersen V, Rosenzweig P. A dietary intervention for recurrent prostate cancer after definitive primary treatment: results of a randomized pilot trial. Urology. 2008;72:1324-8.

43. Nguyen JY, Major JM, Knott CJ, Freeman KM, Downs TM, Saxe GA. Adoption of a plant-based diet by patients with recurrent prostate cancer. Integr Cancer Ther. 2006;5:214-23.

44. Davison BJ, Wiens K, Cushing M. Promoting calcium and vitamin D intake to reduce the risk of osteoporosis in men on androgen deprivation therapy for recurrent prostate cancer. Support Care Cancer. 2012;20:2287-94.

45. Hebert JR, Hurley TG, Harmon BE, Heiney S, Hebert CJ, Steck SE. A diet, physical activity, and stress reduction intervention in men with rising prostate-specific antigen after treatment for prostate cancer. Cancer Epidemiol. 2012;36:e128-36.

46. Ferguson J, Aning J. Prostate cancer survivorship: a nurse-led service model. Br Nurs. 2015;24:S14-21.

47. Baguley BJ, Skinner TL, Leveritt MD, Wright ORL. The impact of a mediterranean-style dietary pattern on cancer-related fatigue and quality of life in men with prostate cancer treated with androgen deprivation therapy: A pilot study. Asia-Pacific Journal of Clinical Oncology. Conference: 43rd Annual Scientific Meeting of the Clinical Oncological Society of Australia, COSA 2016. Australia. 12 (Supplement 5) (pp 115). 2016

48. Baguley BJ, Skinner TL, Leveritt MD, Wright OR. Nutrition therapy with high intensity interval training to improve prostate cancer-related fatigue in men on androgen deprivation therapy: a study protocol. BMC Cancer. 2017;17:1.
49. Aggarwal RR, Rodvelt TJ, Rabow MW, Macaire G, Fedric R, Cortese-Jimenez G, Jay SE. A multidisciplinary clinic to mitigate the impact of androgen deprivation therapy in prostate cancer: a pilot study. J Clin Oncol. 2015;33:218.

50. Joly C, Gotteland C, Rigoli P, Fritschy P, Zilli T. Pichard C, Miralbell R. PP037MON an early nutrition-exercise program can positively affect the body composition and physical function (PF) of frail prostate cancer patients receiving androgen deprivation therapy (ADT). Clin Nutr Suppl. 2012;7:152-3.

51. Focht BC, Lucas AR, Grainger E, Simpson C, Thomas-Ahner JM, Clinton SK. The individualized diet and exercise adherence pilot trial (IDEA-P) in prostate cancer patients undergoing androgen deprivation therapy: study protocol for a randomized controlled trial. Trials. 2014;15:354.

52. Cosby C, Sidhu S, Stringer E. Diet and prostate cancer program: Evaluation and recommendations (DAPPER). Can J Diet Pract Res. 2017;78:151.

53. Golubic M, Schneeberger D, Kirkpatrick K, Bar J, Bernstein A, Weems F, Ehrman J, Perko J, Doyle J, Roizen M. Comprehensive lifestyle modification intervention to improve chronic disease risk factors and quality of life in Cancer survivors. J Altern Complement Med. 2018:24:1085-91.

54. Takada Y, Takagi M, Someya M, Kobayashi T, Aizawa K, Ukon K, Fujita H, Kitsu H, Komatsu T, Yaegashi Y, Sakata Kl, Ikeda H. Nutrition education reduce daily variation of rectal volume and dose in patients with prostate cancer treated with intensity-modulated radiation therapy. Int J Rad Oncol. 2018;102:e144.

55. Goulart J. Living well on Androgen Deprivation Therapy: A comprehensive approach to prostate cancer survivorship. 2014;ClinicalTrials.gov identifier: NCT00065988.

56. Kellogg J. The Men's Eating and Living (MEAL) Study: A randomized trial of diet to alter disease progression in prostate cancer patients on active surveillance. 2010;ClinicalTrials.gov identifier: NCT03173807.

57. McArdle J. Prostate Nutrition and Exercise STudy (ProNEST). 2017; ClinicalTrials.gov identifier: NCT03173807.

58. Maliski S. Staying Strong and Healthy During Androgen Deprivation Therapy (ADT) for men. 2016; ClinicalTrials.gov identifier: NCT02969577.

59. Lee J. Smart After-Care in Patients with Prostate Cancer: a Randomized Controlled Trial. 2017; ClinicalTrials.gov identifier: NCT03264209.

60. Chan J, Usher Newtown R, Culos-Reed SN, Faithfull S, Lambert S, Kenfield SA, Van Blarigan E, Lyons KS, Ramsdill J, Zahavich A, Duncan L, Hart N, Dew M, Moe EL, Dixon C, Winters-Stone KM. An international, population-level initiative to promote healthy lifestyle practices among prostate cancer survivors. J Clin Oncol. 2016;34:e287.

61. Lepore SJ, Helgeson VS, Eton DT, Schulz R. Improving quality of life in men with prostate cancer: a randomized controlled trial of group education interventions. Health Psychol. 2003;22:443-52.

62. Taylor C. Patient satisfaction with information on late effects. Cancer Nurs Pract. 2014;13:16-22.

63. Rutten $\perp$, Arora NK, Bakos AD, Aziz N, Rowland J. Information needs and sources of information among cancer patients: a systematic review of research (1980-2003). Patient Educ Couns. 2005:57:250-61.

64. Cao Y, Ma J. Body mass index, prostate cancer-specific mortality, and biochemical recurrence: a systematic review and meta-analysis. Cancer Prev Res (Phila). 2011;4:486-501.

65. Cao Y, Giovannucci E. Obesity and prostate Cancer. Recent Results Cancer Res. 2016;208:137-53.

66. Smith MR, Finkelstein JS, McGovern FJ, Zietman AL, Fallon MA, Schoenfeld DA, Kantoff PW. Changes in body composition during androgen deprivation therapy for prostate cancer. J Clin Endocrinol Metab. 2002;87:599-603.

67. Rickheim PL, Weaver TW, Flader JL, Kendall DM. Assessment of group versus individual diabetes education: a randomized study. Diabetes Care. 2002;25:269-74.

68. Trento $\mathrm{M}$, Passera $\mathrm{P}$, Tomalino $\mathrm{M}$, Bajardi M, Pomero F, Allione A, Vaccari $\mathrm{P}$, Molinatti GM, Porta M. Group visits improve metabolic control in type 2 diabetes: a 2-year follow-up. Diabetes Care. 2001:24:995-1000.

69. Izquierdo RE, Knudson PE, Meyer S, Kearns J, Ploutz-Snyder R, Weinstock RS. A comparison of diabetes education administered through telemedicine versus in person. Diabetes Care. 2003;26:1002-7.

70. Canadian Cancer Society's Advisory Committee on Cancer Statistics. Canadian Cancer statistics 2015. Toronto, ON: Canadian Cancer Society; 2015.

71. Glasgow RE, Lichtenstein E, Marcus AC. Why don't we see more translation of health promotion research to practice? Rethinking the efficacy-toeffectiveness transition. Am J Public Health. 2003;93:1261-7.

\section{Publisher's Note}

Springer Nature remains neutral with regard to jurisdictional claims in published maps and institutional affiliations. 